\title{
VIABILIDADE AMBIENTAL PARA A CRIAÇÃO DE UNIDADES DE CONSERVAÇÃO NA ILHA DA COROA, MOSSORÓ - RN
}

\section{Environment feasibility for creating conservation units in Ilha da Coroa, Mossoró, Brazil}

\author{
Marisa Carvalho Varela \\ Graduada em Gestão Ambiental pela Universidade do Estado do Rio Grande do Norte \\ Mossoró/RN - Brasil \\ marisacvarela@hotmail.com \\ Rodrigo Guimarães Carvalho \\ Doutorando em Geografia pela Universidade Federal do Ceará \\ Professor Assistente da Universidade do Estado do Rio Grande do Norte \\ Mossoró/RN - Brasil \\ rodrigocarvalho@uern.br
}

Artigo recebido para publicação em 26/02/09 e aceito para publicação em 15/07/09

RESUMO: $\quad$ Esse trabalho visou estudar uma área inserida na planície fluvial do rio Apodi-Mossoró. Trata-se de uma ilha fluvial denominada Ilha da Coroa, situada no bairro Alagados, zona urbana de Mossoró. Procurou-se avaliar vários parâmetros ambientais para verificar a viabilidade de criação de unidades de conservação. Para isso foram realizados levantamentos bibliográficos e da legislação pertinente, análise de fotografias aéreas, aplicação de questionários com moradores e usuários da área, visita a órgãos públicos para a coleta de dados e diversas checagens de campo. Apesar dos indicadores se mostrarem, na sua maioria, desfavoráveis, a possibilidade de criação de unidades de conservação na área da Ilha da Coroa não deve ser descartada devido à grande fragilidade dos ecossistemas fluviais associados à bacia do rio Apodi-Mossoró.

Palavras-chave: Unidades de Conservação. Indicadores Ambientais. Rio Apodi-Mossoró.

ABSTRACT: This paper aims at studying an area inserted in the fluvial lowland of the Apodi-Mossoró river. It is a fluvial island called Ilha da Coroa, situated in the Alagados neighborhood, in the urban area of the municipality of Mossoró. Many environmental parameters were evaluated in order to verify the feasibility of creating conservation units. In order to reach this goal we researched the bibliography and the legislation related to the topic, analyzed aerial photos, applied questionnaires with residents and users of the area, visited public institutions for collecting data and checked the field. Even though most of the indicators are not favorable, the possibility of creating conservation units in Ilha da Coroa should not be discarded, due to the great fragility of the fluvial ecosystems associated to the Apodi-Mossoró river.

Keywords: Conservation Units. Environmental Indicators. Apodi-Mossoró River. 


\section{INTRODUÇÃO}

No Brasil, muitos são os rios que têm suas águas em avançado estado de degradação em conseqüência da falta de efetivação de políticas de gestão do uso e ocupação nas zonas urbanas. Fatores como a degradação das faixas de preservação permanente, ocupação de áreas de várzea para a produção agrícola e a falta de saneamento com descarga de efluentes in natura em cursos d'água fazem das atividades humanas as principais promotoras de degradação dos recursos hídricos. Esses fatores se desenvolvem a despeito de todo arcabouço legal existente no Brasil com intuito de manter a integridade ecológica desse importante componente ambiental e dos ecossistemas associados.

Com o crescimento populacional desacompanhado de intervenções estruturais e políticas eficazes de gestão ambiental, fatores como a poluição doméstica e industrial se agravam, alterando a qualidade ambiental e propiciando o desenvolvimento de doenças de veiculação hídrica, a contaminação da água subterrânea, entre outras. Esse processo, que se agravou principalmente a partir do final da década de 1960, mostrou que o desenvolvimento urbano sem qualquer planejamento ambiental resulta em prejuízos significativos para a sociedade. (TUCCI, 2006).

As mudanças em uma bacia hidrográfica ou em um canal podem variar sob influência do processo de urbanização, estabelecendo-se novas condições de equilíbrio. (CUNHA; LUCAS, 2007). O estudo das condições socioambientais referentes aos rios urbanos tem tido cada vez mais destaque devido à situação caótica evidenciada nos centros urbanos brasileiros, onde os recursos hídricos acabam por receber grandes quantidades de esgotos domésticos, industriais e resíduos sólidos de várias naturezas. Segundo Hespanhol (2006) a situação brasileira é extremamente crítica no que concerne ao saneamento de áreas urbanas, destacando que a porcentagem atendida é de apenas 55\% ficando a frente apenas do Haiti, da Nicarágua e de Belize.

Mossoró tem sua área urbana seccionada pelo Rio Apodi/Mossoró. Nesse setor podem ser observa- dos vários problemas ambientais com impacto direto à qualidade ambiental do rio como o desmatamento e ocupação das áreas de preservação permanente descritas na legislação federal n ${ }^{\circ}$ 471/65 - Código Florestal (na maioria do trecho estas APPs correspondem a cinqüenta metros em faixa marginal), a existência de diversos barramentos e a descarga direta de efluentes urbanos no leito principal. Sazonalmente, no período de maior pluviometria, são comuns as inundações das áreas marginais atingindo vários equipamentos urbanos, desalojando famílias e mais uma série de transtornos para a população de Mossoró.

Para Tucci (2006), as enchentes em áreas urbanas são devidas a dois processos, que ocorrem isoladamente ou de forma integrada: enchentes devido à urbanização, que é provocada devido à ocupação do solo com superfícies impermeáveis e redes de condutos de escoamento; enchentes em áreas ribeirinhas, que são enchentes naturais que atingem a população que ocupa o leito maior dos rios. No caso da área urbana de Mossoró, ambos os casos podem ser evidenciados.

O município de Mossoró possui uma população de 234.390 habitantes, área de $2110 \mathrm{Km}$ quadrados (IBGE, 2007) e não possui nenhuma unidade de conservação dentro dos seus limites territoriais. Segundo Medeiros (2006), a criação de unidades de conservação pode ser considerada importante estratégia de controle do território já que estabelece limites e dinâmicas de uso e ocupação específicos. Este controle e os critérios de uso que normalmente a elas se aplicam são freqüentemente atribuídos em razão da valorização dos recursos naturais nelas existentes ou, ainda, pela necessidade de resguardar biomas, ecossistemas e espécies raras ou ameaçadas de extinção.

Pádua (2002), comentando sobre o aumento em número e extensão das unidades de conservação no Brasil, considera isso uma boa notícia mencionando que "essas criações geralmente recebem elogios de todos os cantos da sociedade, que sem maior análise, as aceitam como beneficios sociais e ambientais". No entanto, a autora acredita que quando se criam unidades de conservação sem justificação eco- 
lógica ou, sem assumir a responsabilidade de sua implantação e manejo efetivos, na verdade se está, em grande medida, enganando a sociedade. Esta autora apresenta algumas indagações que considera, devem ser levadas em conta quando da criação e implementação de unidades de conservação:

- As novas unidades são todas realmente necessárias?

- A categoria escolhida é apropriada?

- O tamanho e a qualidade da nova unidade são ecologicamente suficientes?

- O manejo existe e é apropriado?

- A unidade de conservação tem uso?

As respostas para essas questões percorrem todo o processo de criação das UCs desde o momento da escolha da área, da realização de estudos técnicos que justifiquem o estabelecimento das unidades, da consulta pública, onde devem ser apresentadas em linguagem acessível todas as informações pertinentes a criação de UCs com ampla divulgação principalmente entre os mais interessados, da implementação do manejo e da criação de conselhos gestores.
Considerando os aspectos expostos e a importância no estabelecimento de políticas públicas que possam promover a proteção do rio Apodi/Mossoró, a presente pesquisa buscou analisar indicadores de viabilidade ambiental para a criação de unidades de conservação na Ilha da Coroa, uma ilha fluvial inserida na planície do rio Apodi/Mossoró situada na zona urbana de Mossoró. Foram objetivos específicos deste estudo:

- Identificar o estado de conservação dos recursos naturais na área da Ilha da Coroa;

- Avaliar o processo histórico de exploração da área pela população residente no entorno; - Verificar a viabilidade socioambiental para criação de unidades de conservação na área.

\section{LOCALIZAÇÃO DA ÁREA DE ESTUDO}

A área em análise está inserida na planície fluvial do rio Apodi/Mossoró, no trecho em que este secciona o núcleo urbano da cidade de Mossoró no estado do Rio Grande do Norte. A Ilha da Coroa pode ser visualizada na FIG. 1 correspondendo à área de estudo toda sua extensão e o entorno próximo.

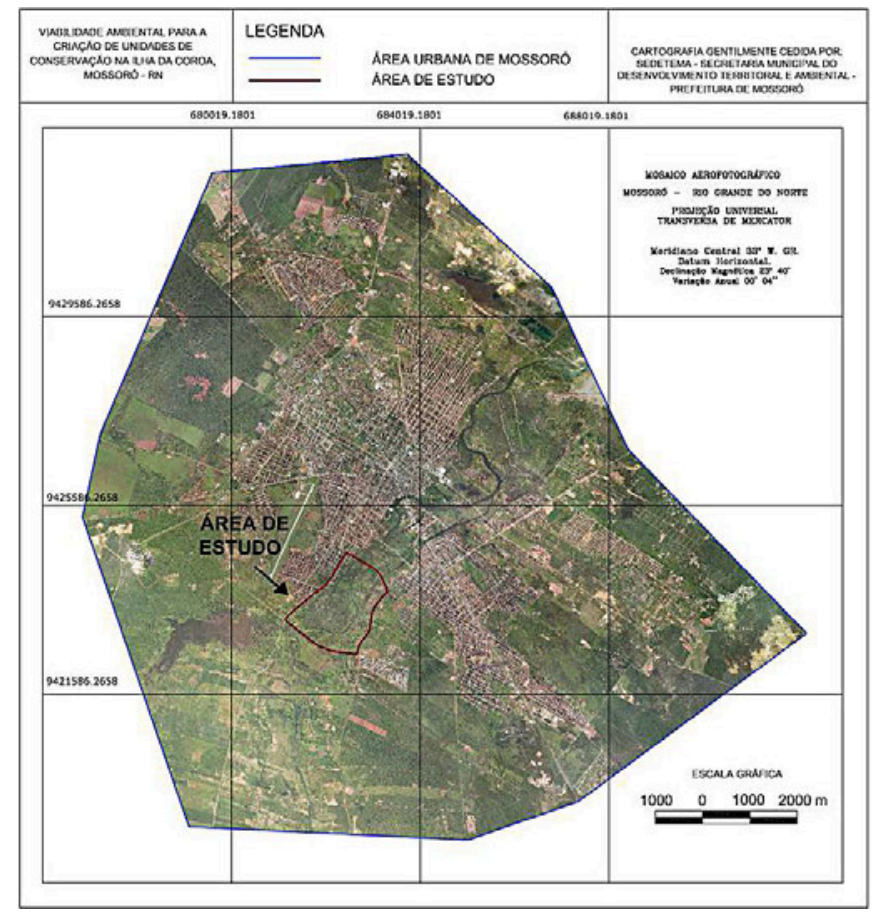

FIGURA 1. Localização geográfica da área.

Fonte: Elaboração própria 


\section{MATERIAL E MÉTODOS}

Esta pesquisa conforme Gil (2008) é classificada como exploratória por objetivar primordialmente conhecer, descrever e interpretar as condições gerais do objeto de estudo segundo parâmetros pré-estabelecidos. No caso específico foram verificados alguns aspectos socioambientais existentes na Ilha da Coroa, com a pretensão de orientar os gestores públicos para a consecução de políticas de proteção ambiental.

Como critérios para a análise da viabilidade de criação de unidades de conservação o presente estudo baseou-se nos indicadores descritos em IBAMA (1999):

- Estado de conservação da área. Uma unidade de conservação deve possuir grande parte de sua área coberta pela vegetação natural da região, com pouca ou quase nenhuma modificação antrópica.

- Presença de espécies raras, endêmicas ou ameaçadas de extinção. Estas espécies são possivelmente as que desapareceriam primeiro caso as modificações em seu habitat continuasse. Assim, elas devem ser consideradas como prioritárias para a conservação.

- Representatividade da região ecológica natural, ou seja, quanto da variação ambiental existente na região ecológica natural (ou ecorregião) está representada na Unidade proposta.

- Complementaridade ao atual Sistema de Unidades de Conservação. Esta medida indica como a unidade de conservação proposta contribuirá para a conservação de ecossistemas ou paisagens ainda não protegidas dentro de uma determinada região ecológica natural.

- Diversidade de ecossistemas e de espécies.

- Área disponível para implantação de uma unidade de conservação.

- Valor histórico, cultural, antropológico e beleza cênica. Esta é uma medida que indica a presença e a quantidade de sítios de grande beleza e valor histórico, cultural e antropológico.

- Grau das pressões humanas sobre a área.

- Situação fundiária ou viabilidade de regularização fundiária.

\subsection{Roteiro Metodológico}

Para o alcance dos objetivos foram seguidas as seguintes etapas operacionais:

- Levantamento bibliográfico através de consulta a literaturas, livros, artigos e meio eletrônico relacionados ao planejamento ambiental, a legislação ambiental, funcionamento e relações dos ecossistemas fluviais.

- Investigação documental com a busca de informações na Gerência Municipal de Gestão Ambiental de Mossoró acerca de dados sobre a área da Ilha da Coroa como mapas, quantidade e distribuição de habitações e o Plano Diretor de Desenvolvimento Urbano. Verificação fundiária junto a Secretaria de Desenvolvimento Territorial e do Meio Ambiente SEDETEMA, constatação dos documentos legais da Ilha da Coroa;

- Análise de fotografias aéreas de 2005 disponibilizadas pela Prefeitura Municipal de Mossoró. A fotointerpretação gerou informações acerca dos limites da Ilha, cobertura vegetal e condições de uso e ocupação das margens. As informações encontram-se georreferenciadas sob a plataforma UTM - SAD 69, zona 24.

- Etapa de Campo - os dados de campo foram obtidos através de visitas a área com a colaboração técnica de alguns professores da Universidade do Estado do Rio Grande do Norte - UERN, Universidade Federal Rural do Semi Árido - UFERSA e Universidade Federal do Piauí - UFPI. As visitas foram indispensáveis para identificação de espécies e impactos ambientais na ilha, bem como, perceber as relações dos moradores com o ambiente. Estes dados foram adquiridos através de observação direta com registros fotográficos e aplicação de entrevista com os moradores do entorno da ilha, mais especificamente, os que relataram ser proprietários de terras ou utilizar o espaço da ilha para alguma atividade de subsistência ou econômica. Foram entrevistados, dessa forma, doze moradores do entorno que foram in- 
dagados sobre diversos aspectos como tempo de utilização dos recursos da ilha, tipos de espécies vegetais encontradas, formas de acesso, entre outras. (QUADRO 1).

- Organização dos dados - fase de síntese dos dados, representação integrada dos temas levantados por meio da definição dos impactos, fragilidades do ambiente natural, potencialidades naturais, recursos existentes, importância da conservação, regulamentação para criação de unidades de conservação. Através da tabulação dos dados coletados nas entrevistas foram gerados gráficos expressando os resultados obtidos.

QUADRO 1. Roteiro das entrevistas

1) Há quanto tempo utiliza a área da ilha?

2) Quais os recursos que utiliza?

3) Quais tipos de culturas são plantadas?

4) Qual o período do ano mais produtivo?

5) Como é feito o acesso a ilha?

6) Quantas pessoas você conhece que utilizam os recursos da ilha?

7) O que mudou na paisagem nos últimos anos?

8) Percebeu alteração no tamanho da ilha?

9) Quais espécies de animais teve a oportunidade de observar na ilha?

10) Quais os impactos no período de cheia para o desenvolvimento de suas atividades?

11) Utilizou areia da ilha para alguma finalidade?

12) Utiliza (ou) a ilha para pastagem de animais ou conhece alguém que utilize?

13) Utiliza (ou) madeira da ilha para alguma finalidade? Ou conhece alguém que utilize?

14) Utiliza a ilha para alguma atividade de lazer?

15) Existe algum conflito de uso entre os moradores?

16) Você concorda em dar um manejo sustentável as suas terras e/ou transformá-la numa Unidade de Conservação? 


\section{RESULTADOS E DISCUSSÃO}

\subsection{Estado de conservação dos recursos naturais - Vegetação}

Com base na análise de fotografias aéreas e levantamentos de campo foi possível gerar um mapa temático de vegetação, considerando duas classes de cobertura vegetal: a primeira retrata as áreas onde a cobertura vegetal arbórea/arbustiva foi suprimida, existindo apenas vegetação rasteira ou culturas de subsistência; a segunda demonstra as áreas onde ainda predominam a vegetação de maior porte, representadas na área principalmente pela carnaúba (espécie nativa) e algaroba (espécie invasora) (FIG. 2).
Com uma área total de 79 ha, a Ilha da Coroa possui 68,5 ha de área com existência de vegetação de porte arbóreo/arbustivo e 10,5 ha correspondendo a áreas onde ocorreu a supressão total da vegetação natural, submetidas a algum tipo de uso como o plantio de culturas ou a pastagem de animais com maior predominância de bovinos e suínos. De uma forma geral, toda a vegetação da Ilha vem sendo modificada através de um uso e ocupação sem controle e predatório promovido pelas famílias que habitam a área de entorno. Mesmo nas áreas com vegetação de porte maior, são marcantes os sinais da degradação promovida pelo homem. As visitas de campo revelaram uma presença expressiva da carnaúba, que é uma espécie vegetal ciliar original do bioma caatinga, competindo em praticamente toda a área da ilha com a algaroba que é uma espécie invasora.

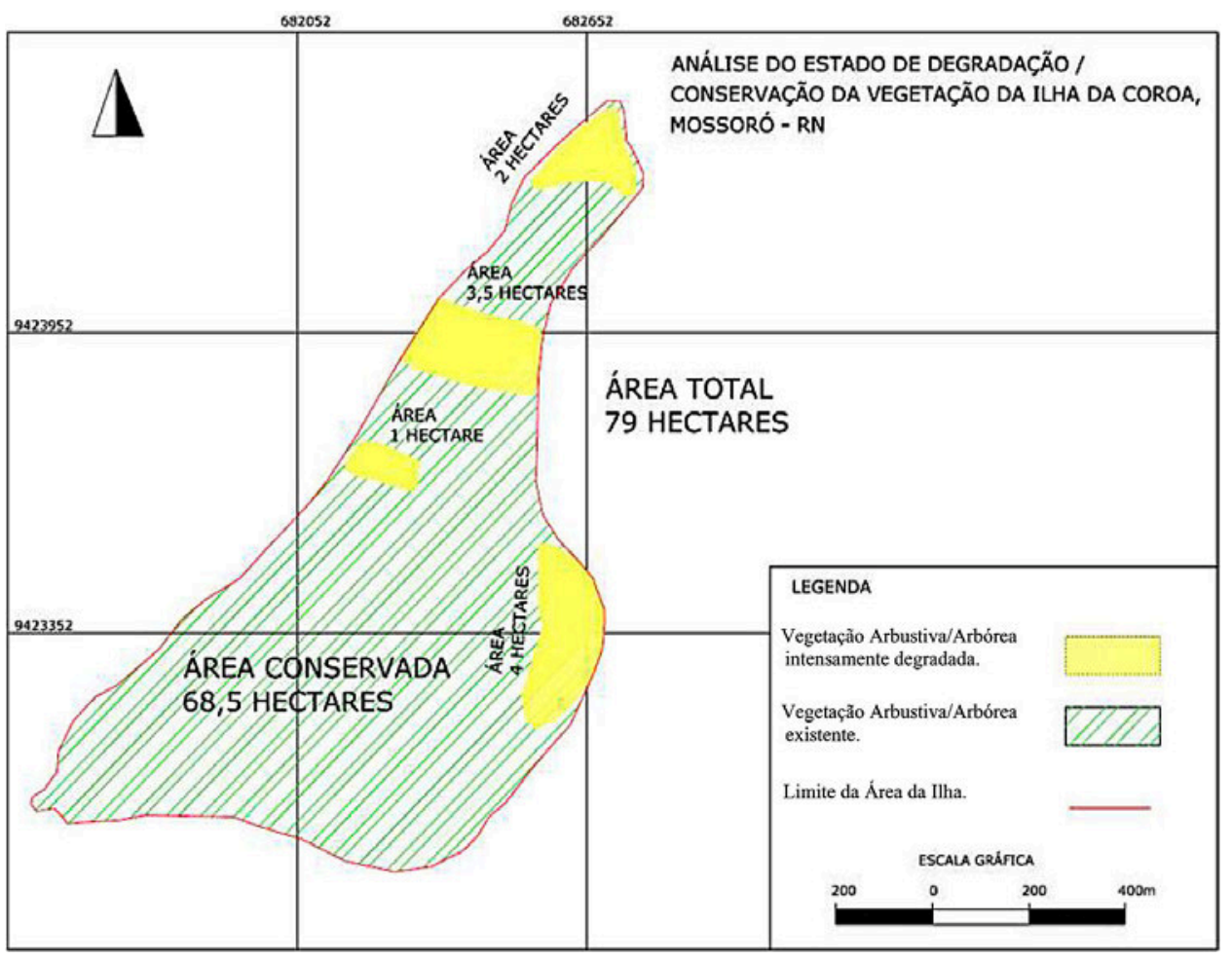

FIGURA 2. Estado de degradação / conservação da vegetação, 2008.

Fonte: Elaboração própria.

Nascimento (2008) verificou em sua pesquisa de doutorado que o cenário de degradação da biodiversidade da caatinga é que abre caminho para a dispersão da algaroba, em especial nas áreas de maior umidade como é o caso da Ilha da Coroa. O autor verificou que nos locais mais próximos ao leito de riachos e desprovidos de mata nativa foram registradas maior população da espécie exótica. À medida que o pesquisador deslocava sua observação para pontos distantes dos riachos, portanto com menos umidade, me- 
nor foi a presença de algarobas, não afetando, dessa forma, a riqueza e diversidade das espécies nativas, mostrando a dificuldade da exótica para invadir ambientes mais secos. Percebe-se deste modo, que a Ilha da Coroa configura-se como uma área vulnerável a ploriferação da algaroba, havendo a necessidade de controle dessa espécie vegetal.

A cobertura vegetal tem uma importância funda-mental no equilíbrio hídrico e sedimentológico da bacia, pois facilita a infiltração de água no solo, reduzindo o escoamento superficial e, consequentemente, a erosão da camada superficial do solo. Desempenha suas funções sistêmicas através da mediação dos fluxos inte-rativos entre água e solos colaborando para a manutenção de padrões de qualidade da água, distribuição de nutrientes e sustentação dos ecossistemas aquáticos.

Foi possível observar (FIG. 3) que em alguns trechos da Ilha houve um intenso desmatamento para utilização dessas áreas na pastagem de animais. Esta situação pôde ser confirmada pelo padrão poligonal das áreas desmatadas, além da existência de troncos expostos após corte raso. O desmatamento também ocorre para dar lugar à plantação de capim e sorgo e utilização da madeira para diversas atividades como: construção de cercas, lenha, cozimento de alimentos, construção civil. O pisoteio dos animais contribui para compactação do solo nas áreas desmatadas e diminuição da diversidade biológica.

Como podemos observar na FIG. 4 as áreas que seriam de preservação permanente previstas em legislação ambiental são cercadas pelos moradores, que descapitalizados e sem informação ocupam indiscriminadamente estas regiões responsáveis pela proteção do leito do rio, imprescindíveis para impedir a erosão e o assoreamento, e também atuando como fonte de abrigo e alimentos aos vários níveis tróficos da fauna limnológica.

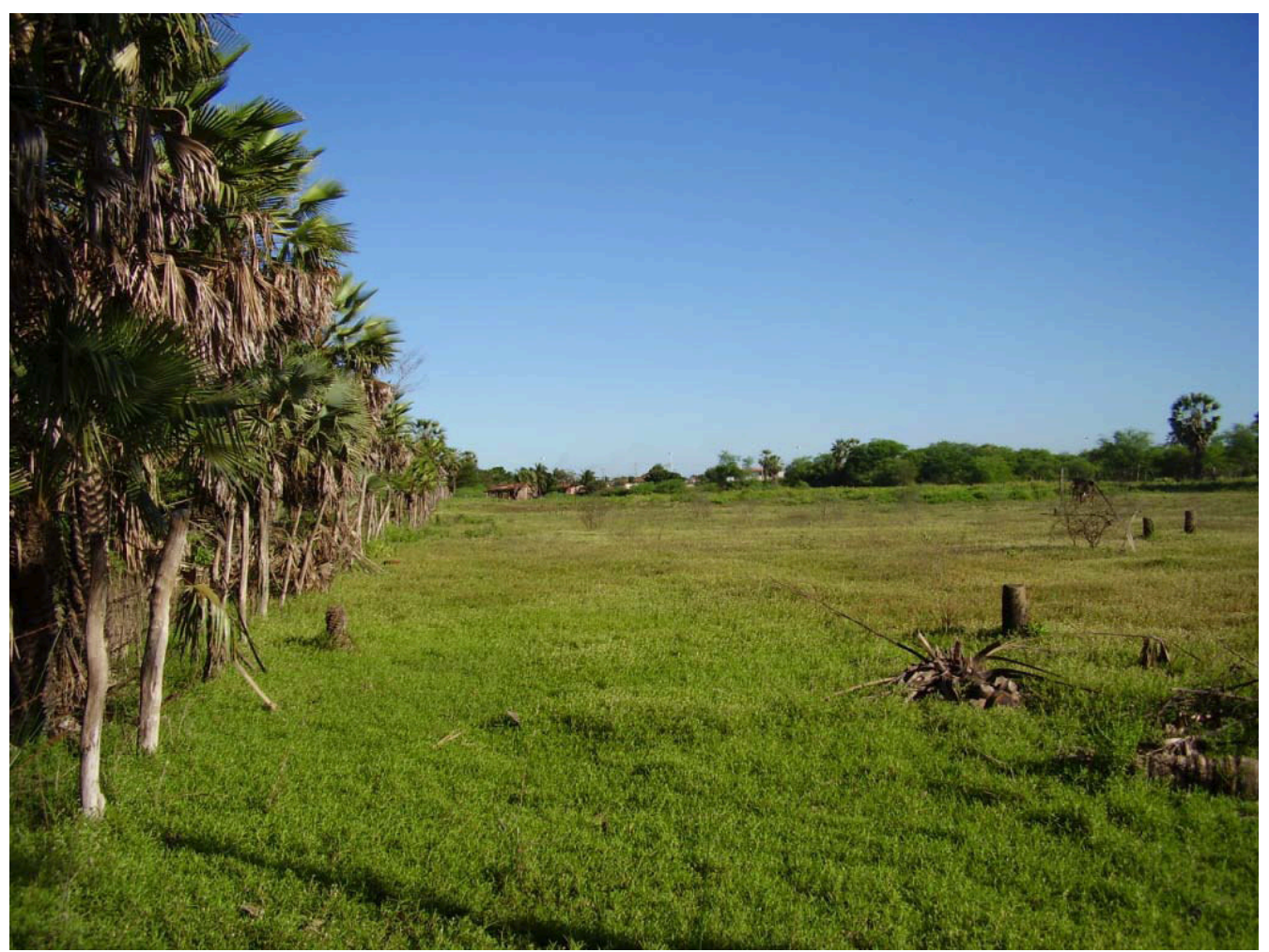

FIGURA 3. Área completamente desmatada ao lado de uma área com vegetação de carnaúba.

Julho de 2008. Foto do autor. 


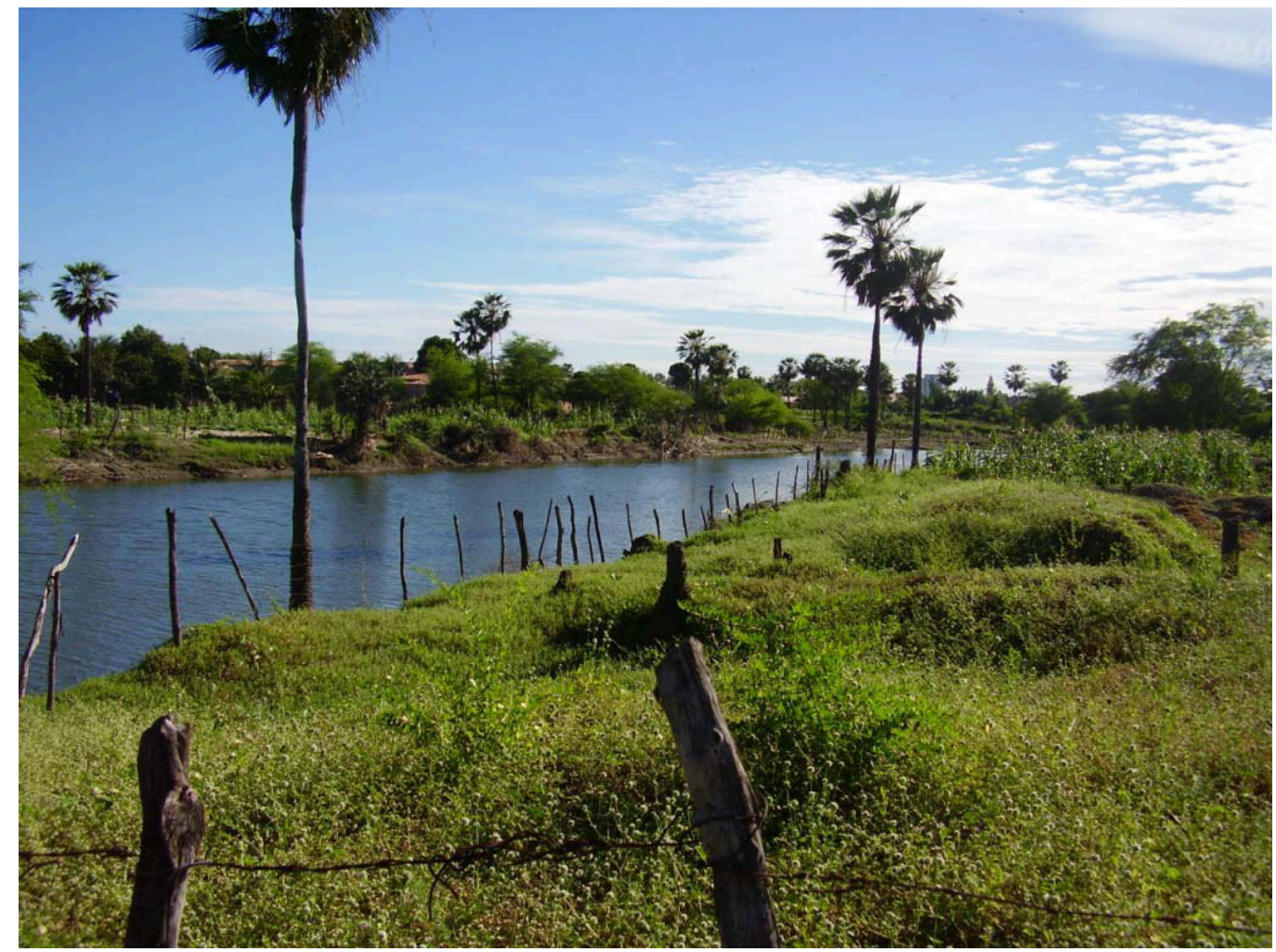

FIGURA 4. Desmatamento nas áreas marginais do rio Apodi/Mossoró. Observar as cercas na margem do rio. Julho de 2008. Foto do autor.

\subsection{Solos}

O solo existente na ilha é o Neossolo flúvico. Atividades de extração de areia realizadas pela população de entorno da Ilha da Coroa puderam ser constatadas por entrevistas abertas com os moradores e também pela visualização direta das áreas degradadas, abandonadas sem a devida recuperação (FIG. 5). Os efeitos dessa ação para o meio ambiente vão desde a retirada da cobertura vegetal, a exposição do solo, até o aumento da remobilização de areia para dentro do canal fluvial, aumentando assim, através do assoreamento, a área de inundação no período de maior precipitação. Além disso, a camada superficial de areia funciona como filtro físico e biológico para as águas subterrâneas e, portanto, sua retirada representa a diminuição destas importantes funções no ecossistema local. Sendo permitido esse tipo de atividade, várias medidas deveriam ser tomadas para a diminuição dos impactos ambientais negativos ao meio ambiente como a imediata recomposição da estrutura vegetal e manejo adequado do solo.

\subsection{Os Canais Fluviais}

Além do assoreamento do rio, há o barramento através de várias pontes de pedra (FIG. 6) ou barro, reduzindo o volume das águas a jusante, comprometendo o fluxo e a dinâmica fluvial natural (FIG. 7), contribuindo ainda para perda de espécies, fato já verificado pelos moradores da área. Essa intervenção se dá por não existir nenhuma forma de acesso permanente à área da Ilha da Coroa. Deste modo, no período de estiagem, quando o rio diminui naturalmente sua vazão, os moradores retomam suas atividades extrativistas e constroem diversas pontes artesanais para facilitar o acesso e o transporte de equipamentos, animais e de mercadorias. 


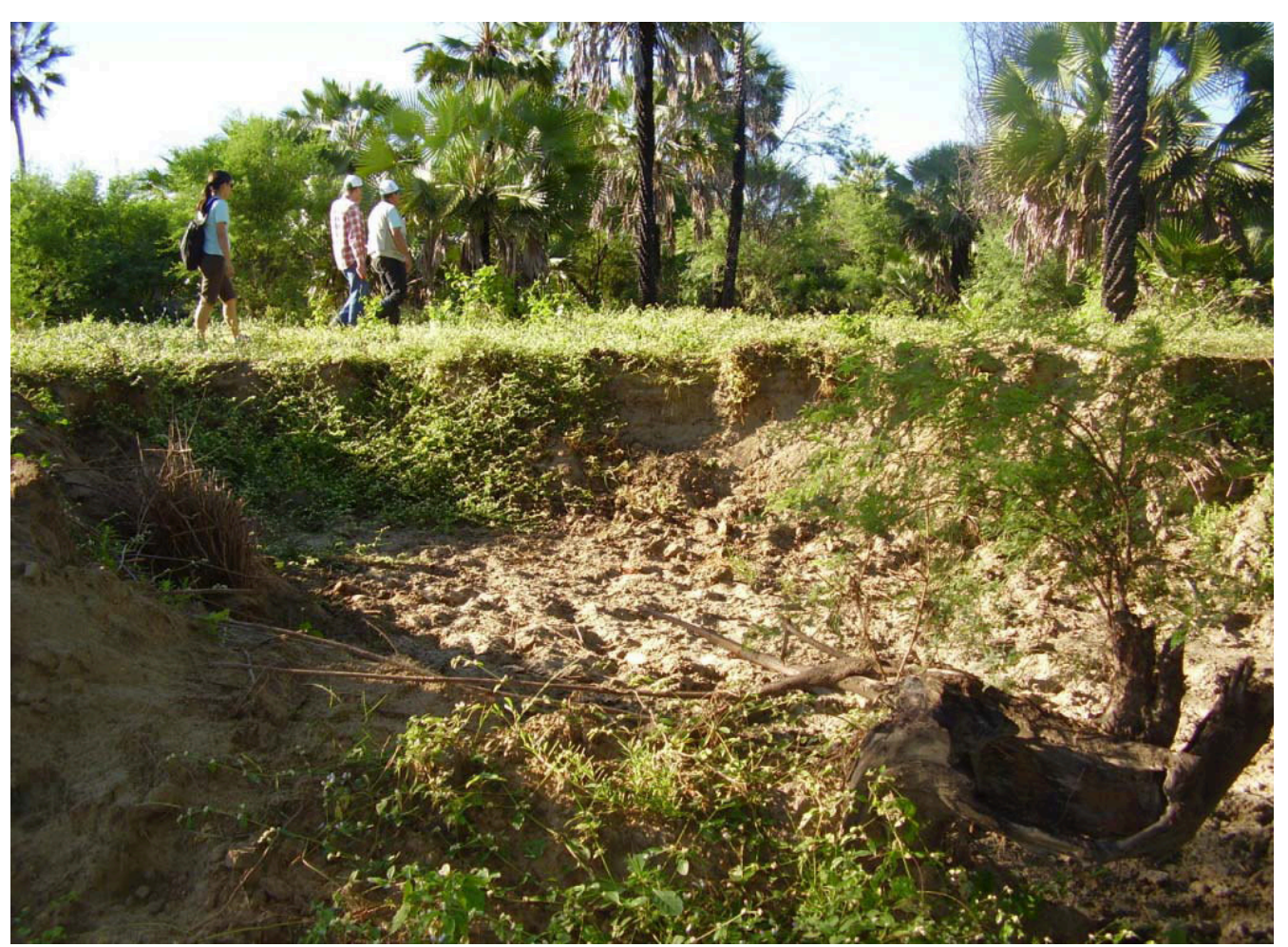

FIGURA 5. Área minerada abandonada na Ilha da Coroa.

Julho de 2008. Foto do autor.

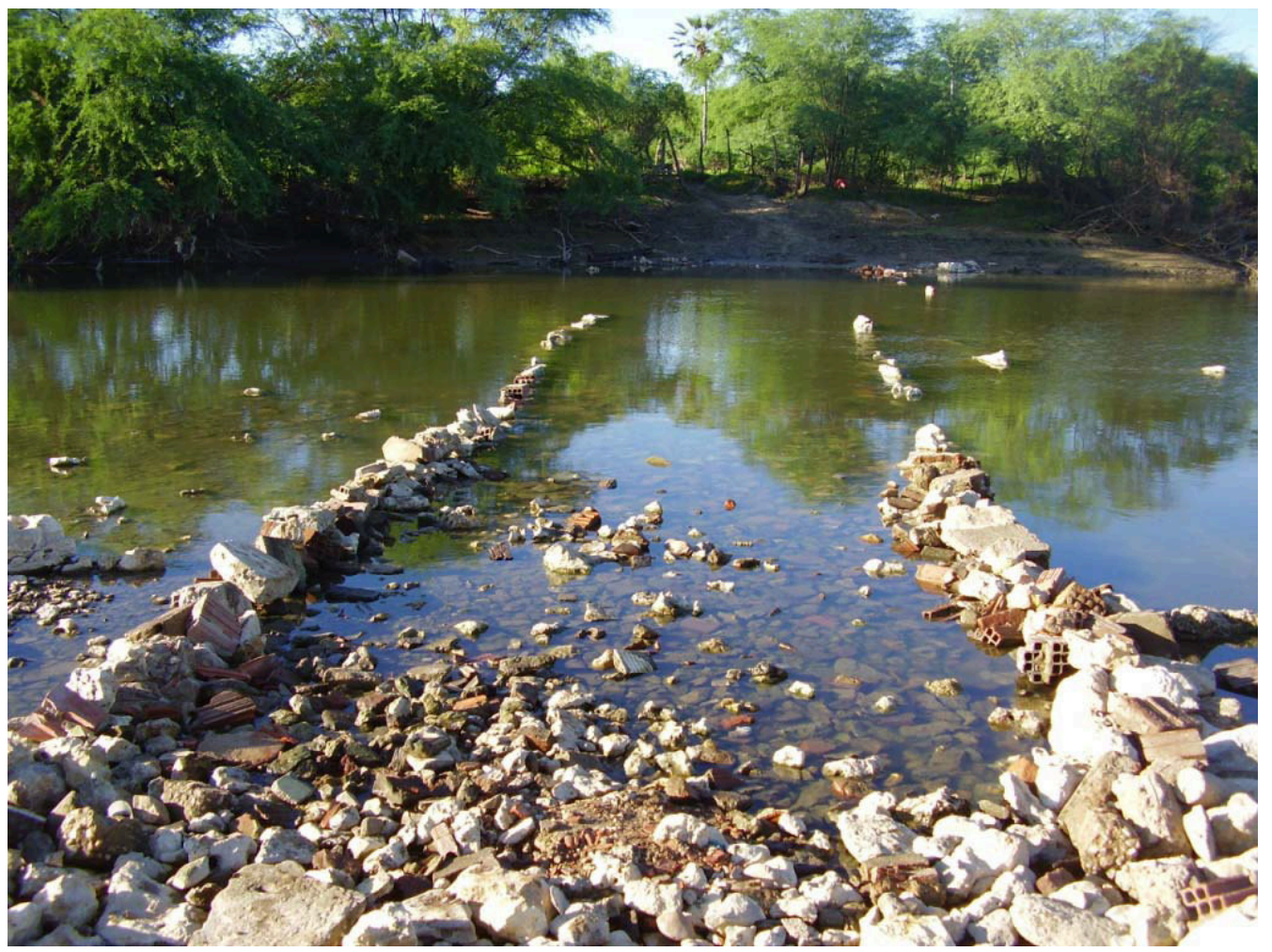

FIGURA 6. Construção de pontes artesanais no leito do rio Apodi-Mossoró para a passagem de pessoas e veículos. Maio de 2008. Foto do autor. 


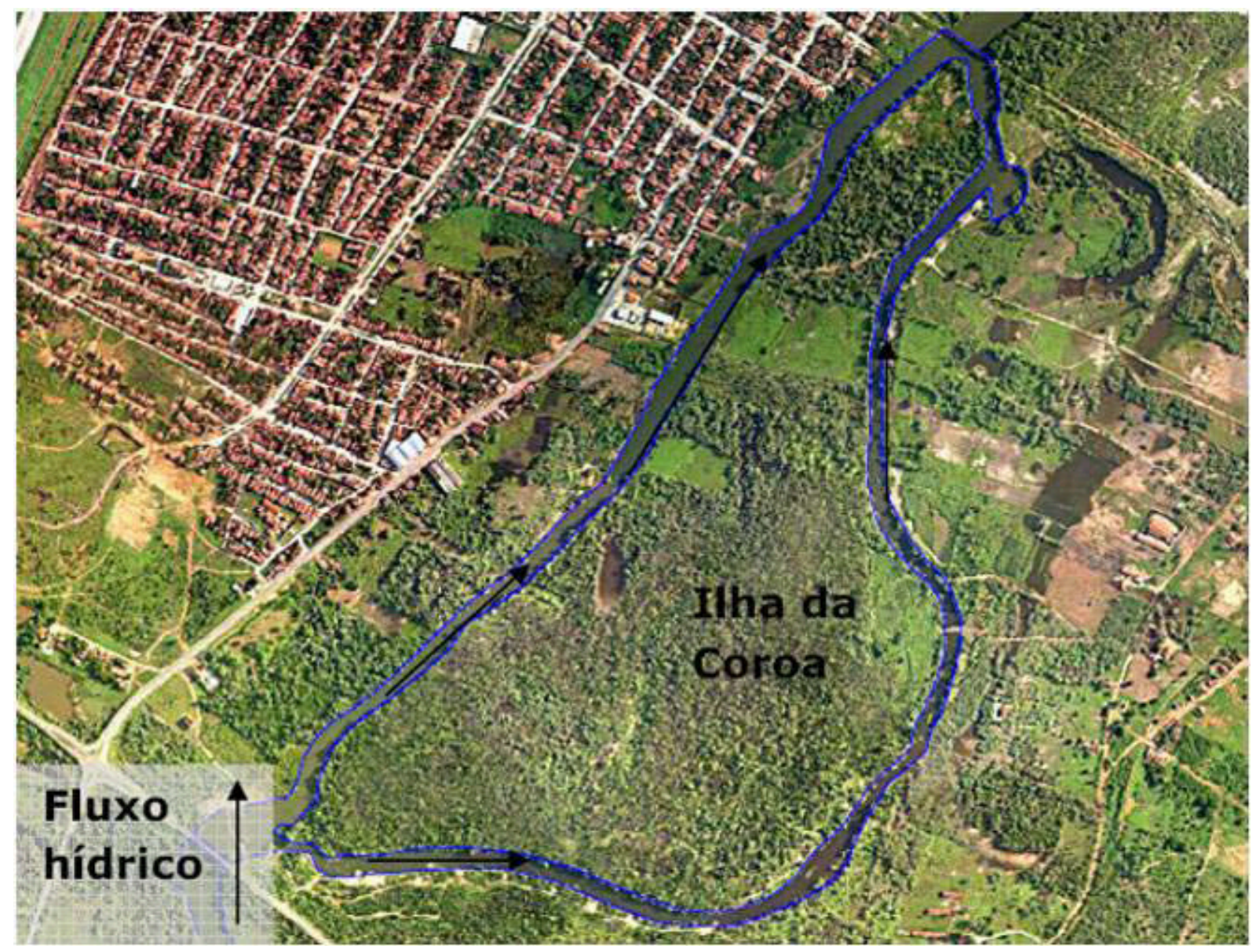

FIGURA 7. Fluxo hídrico fluvial na Ilha da Coroa.

Fonte: Elaboração própria.

\subsection{Percepção dos Moradores e Usuários da Ilha da Coroa}

Através de entrevistas com a população que utiliza os recursos da ilha, foi possível resgatar um pouco da memória local considerando questões referentes à utilização dos recursos naturais, o tempo de exploração desses recursos, qual a diversidade da fauna e flora, os usos destinados ao solo e vegetação, os impactos ocasionados pelas enchentes, período de maior produtividade agrícola, formas de acesso ao local, mudanças no cenário da Ilha e conflitos existentes. Ressalta-se que os dados que serão detalhados a seguir expressam a percepção dos entrevistados, devendo-se considerar que algumas das temáticas investigadas provavelmente não irão corresponder fielmente à realidade dos fatos, mas apenas apontar uma direção, uma primeira exploração do objeto de estudo.

\subsection{Resultados das entrevistas}

Segundo as informações coletadas com os moradores, a área possui atualmente 12 proprietários. Dois deles possuem mais de um terreno, em locais alternados. Quatro utilizam os recursos naturais da ilha há mais de 51 anos e receberam as terras de herança. Na FIG. 8 está discriminado o período de utilização dos recursos naturais da Ilha da Coroa por morador. Destarte, segundo dados da Secretaria de Desenvolvimento Territorial e Ambiental - SEDETEMA, órgão da Prefeitura de Mossoró, apenas duas pessoas possuem documentação de propriedade das terras de toda a Ilha. 


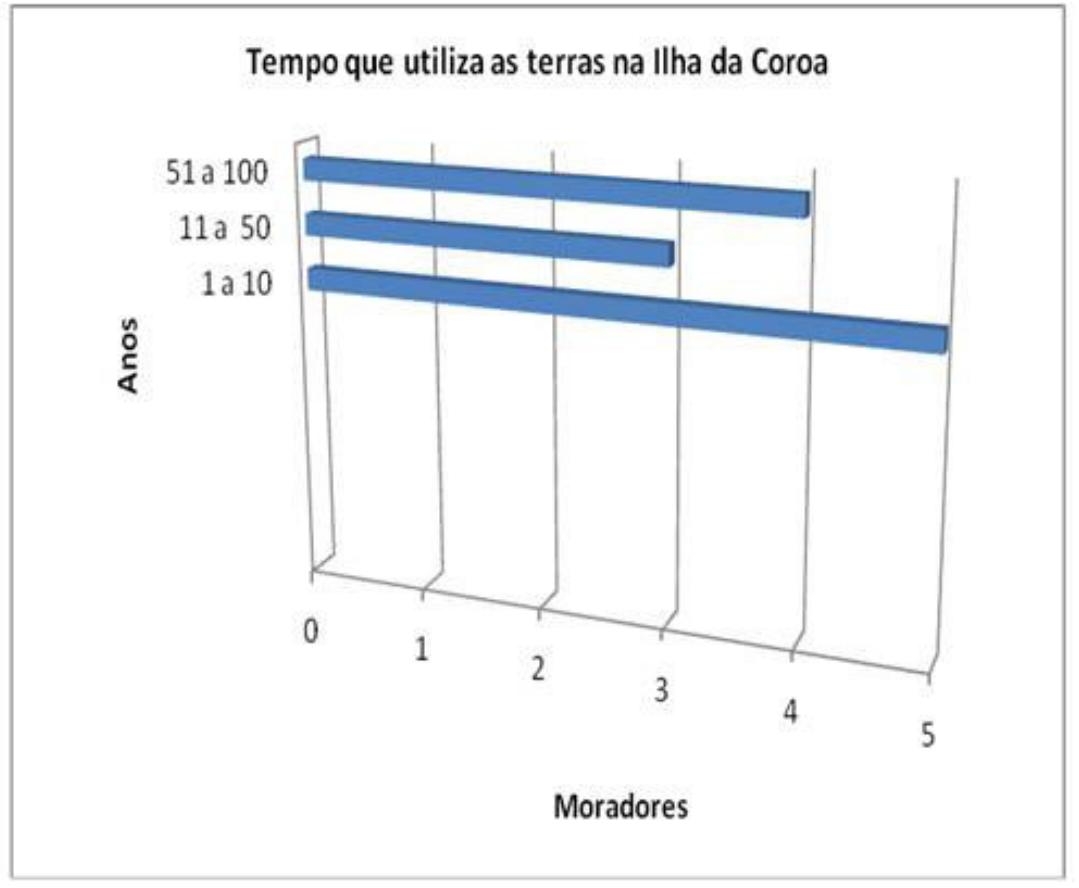

FIGURA 8. Tempo de utilização das terras da Ilha da Coroa. 2008.

Dos entrevistados, 10 acessam a "Crôa", como é conhecida a Ilha da Coroa pelos moradores da região, utilizando pontes de pedra que após as enchentes são refeitas. Do restante, 1 utiliza estrada de barro, que também é levada pela enchente e refeita em seguida, e as outras duas pessoas dizem atravessar a nado, sendo que uma dessas é o proprietário da ponte de barro que atravessa a nado quando a mesma é destruída. (FIG. 9). Uma pessoa que possui ponte de pedra comentou que no passado a travessia era feita de canoa, pois o rio era mais profundo.

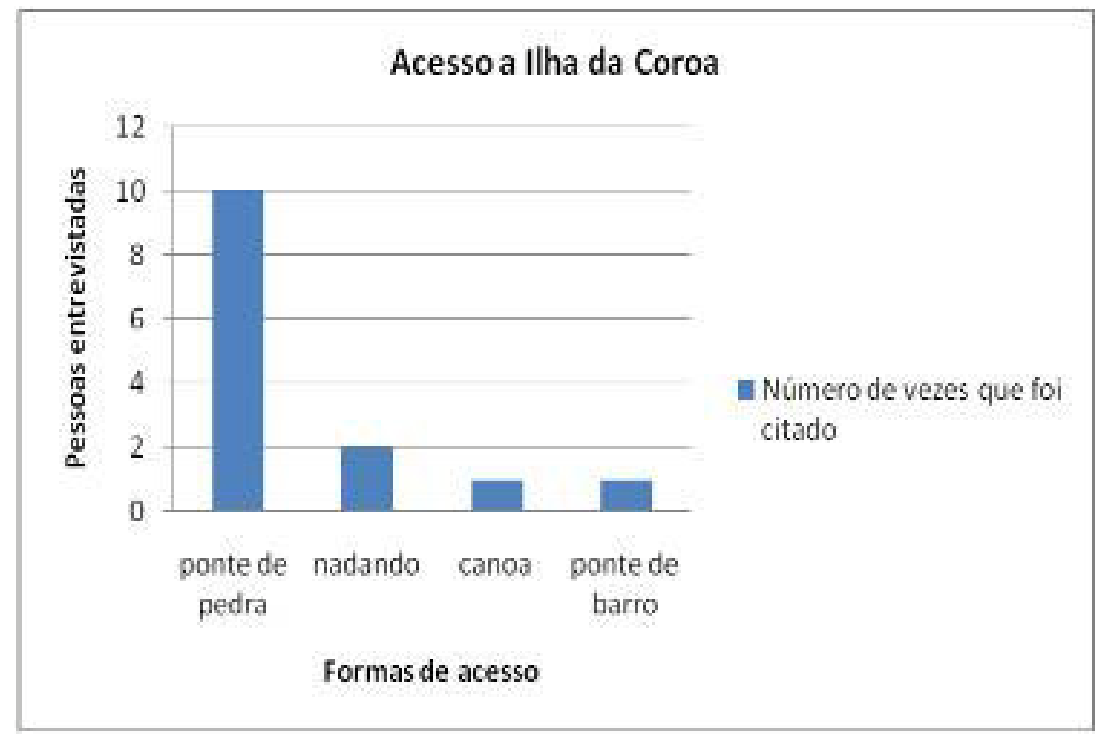

FIGURA 9. Formas de acesso a Ilha da Coroa. 2008. 
Os moradores, tradicionalmente, vendiam areia extraída da Ilha que era utilizada na construção civil e também fabricavam tijolos. Os que o faziam afirmaram não ser oportuno fazê-lo no momento, pois o IBAMA colocou restrições quanto à utilização das áreas de preservação permanente, marginais ao rio, que devem ser preservadas em 50 metros a partir de cada margem. Também comentaram sobre a taxa de dois mil reais cobrada ao ano pela licença ambiental, que segundo eles, inviabiliza a produção. A madeira é reti- rada e utilizada nos fornos para a fabricação dos tijolos, na produção de carvão, como lenha no cozimento de alimentos e para construção de suas cercas. Os solos são utilizados por $75 \%$ dos moradores para o cultivo principalmente do capim e sorgo, usado na alimentação do gado. Grande quantidade planta feijão e mitho para consumo e venda. Ainda plantam para o consumo de hortaliças, jerimum, batata, macaxeira, coqueiro, banana, limão, laranja, cajá, acerola, goiaba, manga e siriguela (FIG. 10).

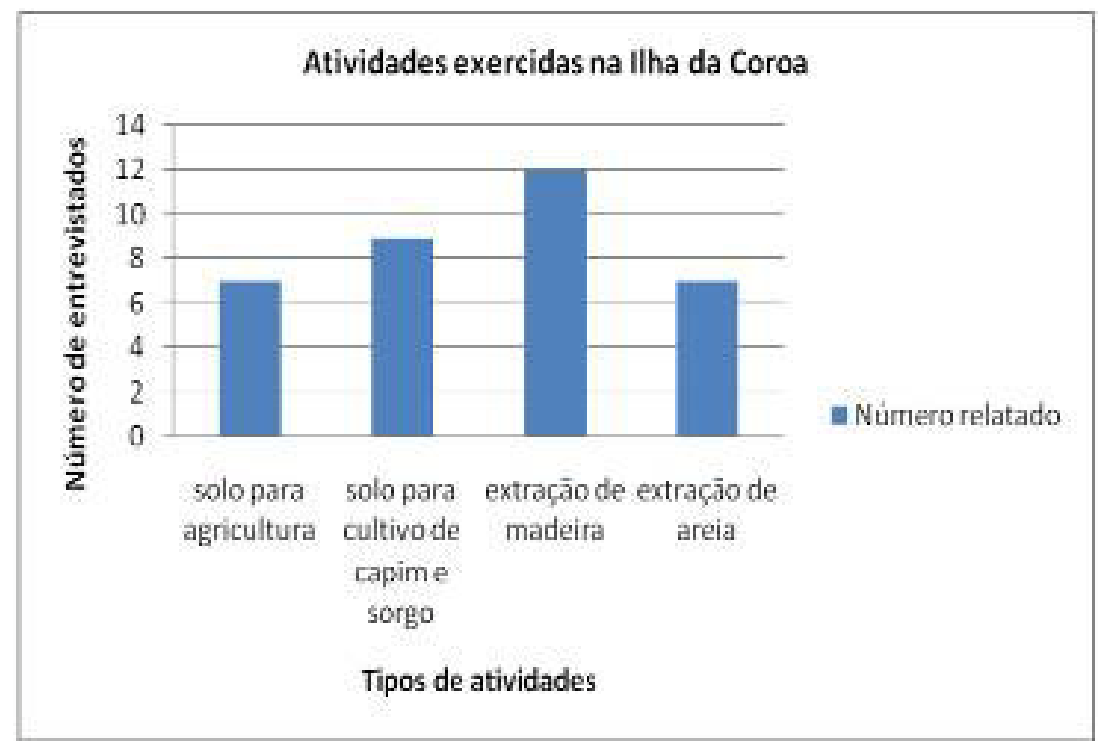

FIGURA 10. Atividades de uso e ocupação na Ilha. 2008.

A Ilha também é utilizada para pastagem de animais por 8 donos de terras. No passado, todos os entrevistados realizavam essa atividade, mas devido às pressões do IBAMA, alguns (os que dispõem de outras atividades comerciais) remanejaram seus animais para outros locais, distante do adensamento urbano. Um dos moradores comentou que além de gado cria porcos na Ilha, e ainda que durante essa semana perdeu quatro deles, vítimas de picada de cobra. Eles também possuem cavalos e burros para ajudar no transporte de mercadorias. Um dos moradores que reside no lado leste da Ilha, onde o rio é bem mais volumoso, afirma não utilizá-la para pastagem, mas somente para plantação do capim. Citou que seu terreno na outra margem é grande, sendo suficiente para pastagem dos seus animais.
Um dos questionamentos da entrevista fez referência à biodiversidade do local. Dez pessoas falaram que há muita carnaúba, ressaltando que já houve uma maior quantidade. A algaroba é citada por 8 pessoas como existente em suas terras, e que a quantidade foi reduzida ao ser utilizada para produção de cerca, lenha e carvão. Essas informações estão condizentes com a pesquisa de campo onde a carnaúba foi verificada como a representante do bioma caatinga de maior expressão. Já a algaroba, uma espécie exótica e bem adaptada ao quadro climático da semi-aridez, tem encontrado condições naturais favoráveis para se multiplicar na Ilha da Coroa, tendo como fator limitante o uso humano para diversos fins.

Ainda, entre os entrevistados, 4 disseram que 
a oiticica já foi uma espécie bem presente na região. $\mathrm{O}$ limoeiro, bananeira, mangueira, pé de pinha são espécies frutíferas ainda encontradas na Ilha segundo o relato de 2 pessoas. As árvores pau d'arco, quixabeira e juazeiro são citadas por 1 pessoa como ainda existentes em suas terras. Árvores como catingueiro, marmeleiro e juazeiro foram citadas por 3 pessoas como presentes na Ilha em épocas passada, sendo que do juazeiro ainda existem remanescentes. Um dos donos de terras cita o marizeiro, pereiro, velame, aroeira, cumaru, mufumbo e a jurema como espécies existentes no passado. Este mesmo entrevistado tem as seguintes espécies do gênero das frutíferas em suas terras: acerola, goiaba, manga, cajarana, siriguela, laran- ja, castanhola e imbuzeiro (QUADRO 2).

Quanto às espécies de peixes foram relatados os seguintes: tilapia, tucunaré, curimatã, piaba, traíra, pial, cascudo e carão, sendo os mais citados os três primeiros. O camarão no gênero crustáceo foi citado por duas pessoas. Foram citadas 20 espécies de pássaros. São eles o Galo-de-campina, currupio, garça, graúna, canário, rolinha, bigode, galinha d'água, sabiá, asabranca, azulão, papa-capim, pintasilgo, golinha, xexéu, patoí, periquito-italiano, avuete, casaca de couro, pardal. Nos gêneros mamíferos e répteis foram citadas as seguintes espécies: preá e peba (mamíferos), camaleão, cascavel, cobra de veado, jararaca e teju (répteis).

QUADRO 2. Lista de algumas espécies da ilha da coroa segundo os entrevistados

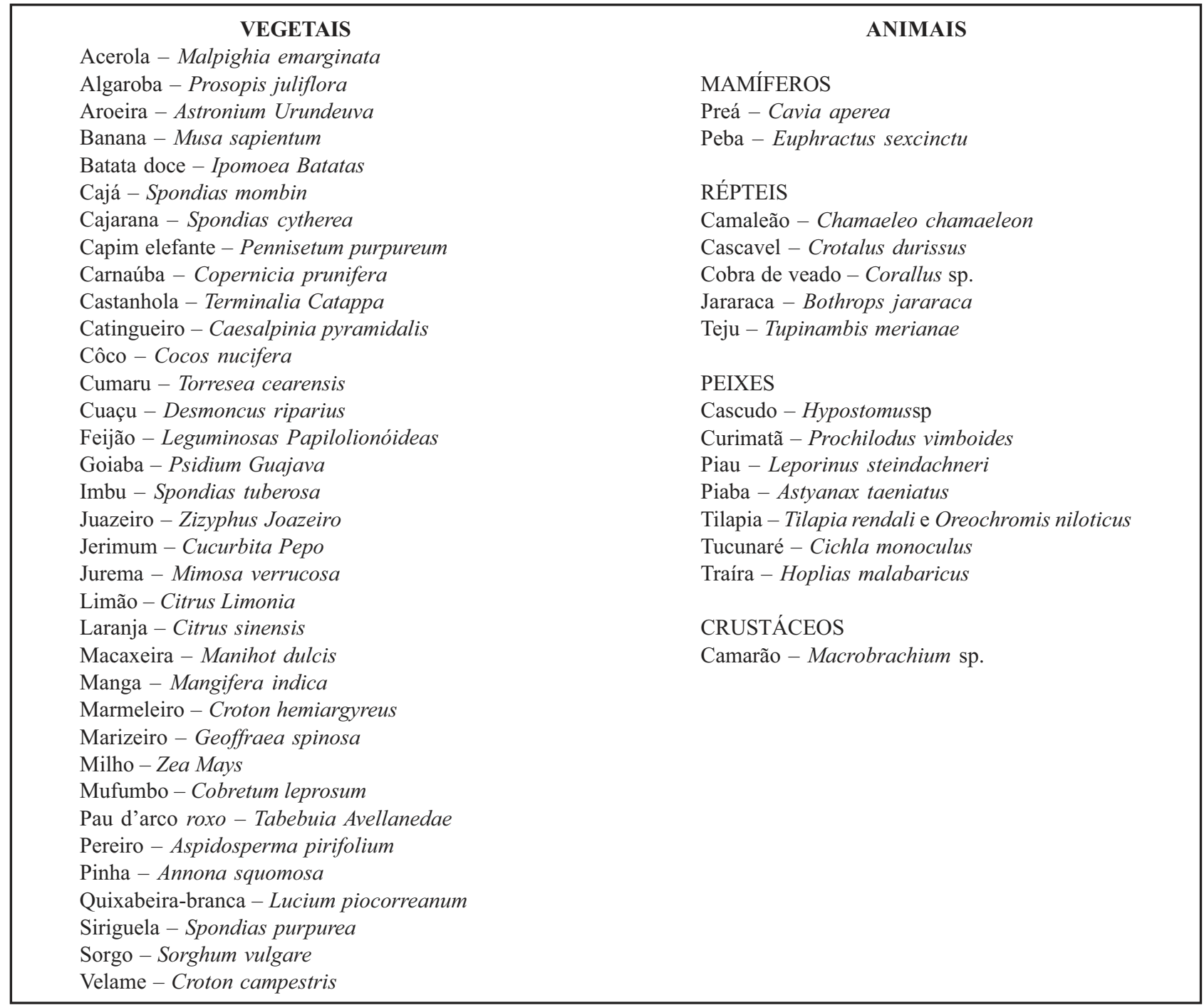

Fonte: CORREAA, Pio. Dicionário de plantas úteis do Brasil e das exóticas cultivadas. Rio de janeiro, Imprensa Nacional, 1972-1978.p, 459, 584. 
Todos os entrevistados mostraram ter alguma relação afetiva com a ilha, relatando já ter usado o espaço para atividades de lazer, tomar banho, e alguns até lavar roupas e beber água do rio Apodi/Mossoró. Dois moradores disseram haver conflito por terras da Ilha, somente no sentido do vizinho avançar alguns metros para dentro do terreno ao lado. Todos reclamam da falta de segurança no local, e da entrada de estranhos para roubar e usar drogas.

Dos 12 proprietários 11, quando indagados sobre a possibilidade de terem suas terras transformadas em uma Unidade de Conservação, disseram concordar, "pois do jeito que está não daria para continuar", visto não conseguirem mais dar continuidade a todas as atividades produtivas em face das interdições por parte das leis ambientais. Um deles comentou já ter procurado o IBAMA com a finalidade de pedir ajuda técnica para manejar adequadamente suas terras, e também para ajudar na segurança do local. Outro que foi autuado pelo órgão disse ter disponibilizado suas terras para serem utilizadas como área de preservação.

\subsection{Avaliação dos Indicadores}

Dos indicadores analisados, concluiu-se que a maioria não é completamente atendida no caso da Ilha da Coroa. A área apresenta-se bastante degradada e com pouca diversidade biológica. A complementaridade ao atual sistema de unidades de conservação e a representatividade da região ecológica natural, comandada por condições climáticas semi-áridas com grande representatividade do bioma caatinga, não são expressivos, por si só, para justificar a conservação da ilha tendo em vista a forte degradação ambiental presente e até mesmo pelo fato de ser uma pequena área territorial, de aproximadamente 79 ha. No que tange a área disponível para a criação de unidades de conservação, destaca-se que, apesar de pequena, a área praticamente não apresenta benfeitorias o que pode favorecer a criação de unidades de proteção integral a um baixo custo indenizatório para o poder público. Não foi verificado com a pesquisa um significativo valor histórico ou antropológico, salvo para as populações tradicionais que utilizam a ilha, porém, existe uma gran- de beleza cênica que possibilita a utilização da área para projetos de educação ambiental, trilhas ecológicas e turismo de aventura. Um fator de entrave para essas atividades é a falta de segurança relatada pelos moradores. As pressões humanas sobre a área ainda são muito fortes, tendo como fator limitante o precário acesso à ilha e a fiscalização do IBAMA que tem gerado incômodos aos moradores e desencorajado algumas práticas ilegais. A questão fundiária retrata um uso e ocupação tradicional, onde somente dois moradores possuem documentação e outros dez utilizam a área como posseiros.

Apesar dos indicadores se mostrarem na sua maioria desfavoráveis, a possibilidade de criação de unidades de conservação na área da Ilha da Coroa não deve ser descartada devido a grande fragilidade dos ecossistemas fluviais. A necessidade de proteção e regulação de uso dos recursos naturais da ilha deve ser pensada em conjunto com as atuais formas de apropriação da área. A criação de uma unidade de uso sustentável na parte mais degradada da ilha e uma de proteção integral na área com maiores resquícios de vegetação natural pode ser negociada entre os agentes envolvidos, sendo observada uma predisposição conjunta dos moradores da área e da gestão pública municipal. Para a área de uso sustentável devem ser propostas formas de utilização com um manejo adequado, para garantir o sustento de várias famílias que sobrevivem dos recursos da ilha.

\section{CONCLUSÃO}

Foram avaliados neste trabalho alguns indicadores de viabilidade para criação das unidades de conservação da Ilha da Coroa. Cabe salientar que tais indicadores apenas servem para balizar a proposições acerca da criação de unidades de conservação, não sendo assim, determinantes, mas sim, orientadores na tomada de decisão. Muitas vezes, a presença de um único atributo ambiental pode justificar a criação de uma unidade de conservação, como, por exemplo, em uma praia que ocorra a reprodução de tartarugas marinhas, ou então, uma área onde exista uma grande concentração de cavernas, ou ainda uma área com uma exposição rochosa que tenha valor paisagístico ou cul- 
tural. O importante neste processo é sempre manter o bom senso. Atualmente, observa-se que muitas unidades são criadas em virtude, inicialmente, de uma manifestação popular. Essa interação se mostra bastante importante tendo em vista que a unidade já nasce respaldada pela vontade da sociedade, que também tem o dever de protegê-la para as futuras gerações.

\section{REFERÊNCIAS}

BRASIL. Lei no 4.771 - 15 Set. Institui o Novo Código Florestal. Brasília, DF: Senado Federal, 1965.

CUNHA, S. B. DA E LUCAS, L. M. Rede de drenagem urbana em área tropical: mudanças na morfologia do canal e níveis de poluição das Águas - rio dos Macacos - Rio de Janeiro - RJ. GEOUSP - Espaço e Tempo, São Paulo, n. 22, p. 39 - 64, 2007.

GIL, A. C. Como elaborar projetos de pesquisa. $4^{\mathrm{a}}$ Ed. São Paulo: Atlas, 2008.

HESPANHOL, I. Água e saneamento básico. In: REBOUÇAS, A. da C. et al. Águas doces no Brasil capital ecológico, uso e conservação. 3 ed. São Paulo: Escrituras Editora, 2006.

INSTITUTO BRASILEIRO DO MEIO AMBIENTE E DOS RECURSOS NATURAIS RENOVÁVEIS IBAMA. Critérios para a análise de viabilidade de criação de unidades de conservação, 1999. Disponível em <http://www.ibama.gov.br/siucweb/guiadechefe/ guia/c-1 corpo.htm>. Acesso em ago. 2008.

INSTITUTO BRASILEIRO DE GEOGRAFIA E ESTATÍSTICA - IBGE. Censo Demográfico 2007. Disponível em <http://www.ibge.gov.br/cidadesat/ topwindow.htm?1>. Acesso em de jun. 2008.

MEDEIROS, R. Evolução das tipologias e categorias de áreas protegidas no Brasil. Ambiente e sociedade. v. 9, n.1 Campinas - Jan/Jun. 2006.

NASCIMENTO, C. E. de S. Comportamento invasor da algarobeira Prosopis juliflora (Sw) DC. Nas planícies aluviais da caatinga. Tese (Doutorado em Bi- ologia Vegetal) - Universidade Federal de Pernambuco, UFPE, Brasil, 2008.

PÁDUA, M. T. J. Unidades de Conservação, muito mais do que atos de criação e planos de manejo. In: MILANO, M. S. et al. Unidades de Conservação: atualidades e tendências. Fundação O Boticário de proteção à natureza, 224p. Curitiba, 2002.

TUCCI, C. E. M. Água no meio urbano. In: REBOUÇAS, A. da C. et al. Águas doces no Brasil capital ecológico, uso e conservação. 3 ed. São Paulo: Escrituras Editora, 2006. 